\title{
Photocatalytic Degradation of Nitro and Chlorophenols Using Doped and Undoped Titanium Dioxide Nanoparticles
}

\author{
Hassan Ilyas, Ishtiaq A. Qazi, Wasim Asgar, M. Ali Awan, and Zahir-ud-din Khan \\ School of Civil and Environmental Engineering, National University of Sciences and Technology, H-12, Islamabad, Pakistan \\ Correspondence should be addressed to Hassan Ilyas, hassan@iese.edu.pk
}

Received 19 February 2010; Revised 13 April 2010; Accepted 1 June 2010

Academic Editor: William W. Yu

Copyright () 2011 Hassan Ilyas et al. This is an open access article distributed under the Creative Commons Attribution License, which permits unrestricted use, distribution, and reproduction in any medium, provided the original work is properly cited.

Pure and $\mathrm{Ag}-\mathrm{TiO}_{2}$ nanoparticles were synthesized, with the metallic doping being done using the Liquid Impregnation (LI) method. The resulting nanoparticles were characterized by analytical methods such as scanning electron micrographs (SEMs), Energy Dispersive Spectroscopy (EDS), and X-ray diffraction (XRD). XRD analysis indicated that the crystallite size of TiO $\mathrm{T}_{2}$ was $27 \mathrm{~nm}$ to $42 \mathrm{~nm}$ while the crystallite size of $\mathrm{Ag}_{-} \mathrm{TiO}_{2}$ was $11.27 \mathrm{~nm}$ to $42.52 \mathrm{~nm}$. The photocatalytic activity of pure $\mathrm{TiO}_{2}$ and silver doped $\mathrm{TiO}_{2}$ was tested by photocatalytic degradation of $p$-nitrophenol as a model compound. Ag- $\mathrm{TiO}_{2}$ nanoparticles exhibited better results (98\% degradation) as compared to pure $\mathrm{TiO}_{2}$ nanoparticles ( $83 \%$ degradation) in 1 hour for the degradation of $p$-nitrophenol. $\mathrm{Ag}-\mathrm{TiO}_{2}$ was further used for the photocatalytic degradation of 2,4-dichlorphenol (99\% degradation), 2,5dichlorophenol (98\% degradation), and 2,4,6-trichlorophenol (96\% degradation) in 1 hour. The degree of mineralization was tested by TOC experiment indicating that 2,4-DCP was completely mineralized, while 2,5-DCP was mineralized upto 95 percent and 2,4,6-TCP upto 86 percent within a period of 2 hours.

\section{Introduction}

Advanced oxidation processes (AOPs) are techniques used for the degradation of harmful organic pollutants resistant to conventional treatment methods. AOPs depend on in situ generation of highly reactive radical specie such as $\mathrm{OH}^{*}$ that breakdown a number of organic compounds without being selective [1-3] using chemical or light energy. The process employing a semiconductor activated by UV or visible light to degrade aquatic or atmospheric pollutants is called photocatalysis which results in partial or complete mineralization of the organic compounds $[4,5]$.

Titanium dioxide $\left(\mathrm{TiO}_{2}\right)$, a metal oxide semiconductor has been found to be one of the most effective photocatalysts due to its high efficiency and stability. $\mathrm{TiO}_{2}$ has a band gap of $3.2 \mathrm{eV}$ that allows UV light to excite the valance electrons and inject these into the conduction band leaving holes in the valance band [6]. The high rate of electronhole recombination in $\mathrm{TiO}_{2}$, however, limits the efficiency of the photocatalyst which can be arrested, to some extent, by doping with metallic elements such as silver [7]. On the other hand, the antibacterial action of silver, particularly in the colloidal form, is also well known [8].

Metal-doped titanium dioxide has been used for the degradation of many organic pollutants in general $[2,3]$ and for phenols in particular [9-11]. Chlorophenols have low taste and odour thresholds and exhibit high toxicity and carcinogenic character [9]. They are very toxic and poorly biodegradable compounds, that are not effectively degraded by direct biological methods [10]. Consequently, their elimination in wastewaters and drinking water is of great interest.

In the present work, $\mathrm{TiO}_{2}$ nanoparticles were synthesized by calcination while metallic doping with silver was achieved using Liquid Impregnation [12]. These nanosized catalysts were characterized by the techniques such as X-ray diffraction (XRD), Scanning Electron Microscopy (SEM), and Energy Dispersive Spectroscopy (EDS). Photocatalytic degradation using the nanosized particles was then studied with p-nitrophenol as a model compound followed by of 2,4-dichlorophenol, 2,5-dichlorophenol, and 2,4,6trichlorophenol. 


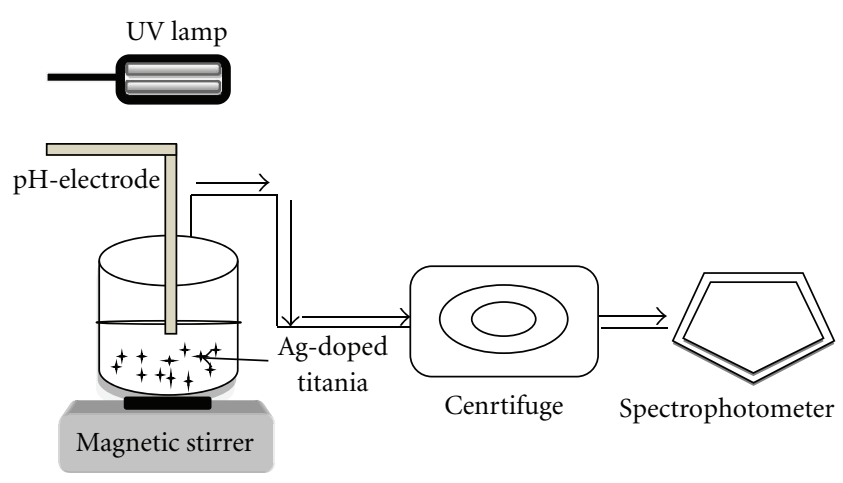

Figure 1: Schematic Diagram of Experimental Setup of Photocatalysis.

\section{Experimental}

2.1. Materials. $\mathrm{TiO}_{2}$ (GPR, BDH Chemicals Ltd. Poole England), $\mathrm{AgNO}_{3}$, p-nitrophenol (purity 99\%), 2,4-dichlorphenol, 2,5-dichlorophenol, and 2,4,6- trichlorophenol (GR, Merck, Germany).

2.2. Photocatalyst Preperation. In case of pure $\mathrm{TiO}_{2}$ nanoparticles, $\mathrm{TiO}_{2}$ was calcined at $500^{\circ} \mathrm{C}$ for 3 hours, to abtain the nanosized crystal structure. Silver-doped $\mathrm{TiO}_{2}$ nanoparticles were prepared by following the method of reference [12] described below.

$1 \mathrm{~g} \mathrm{TiO}_{2}$ was added to $100 \mathrm{ml}$ dionized water in a $500 \mathrm{ml}$ Pyrex beaker. For silver doping 1\% (molar ratio) of $\mathrm{AgNO}_{3}$ was also added to the suspension. The resulting slurry was thoroughly mixed by vigorous stirring and allowed to settle, at room temperature, over night. The liquid so obtained was dried in an oven at $100^{\circ} \mathrm{C}$ for 12 hours to get rid of any remaining moisture. The solid material resulting from this step was calcined, at $500^{\circ} \mathrm{C}$ for 3 hours in a furnace. This resulted in fine particles of silver-doped $\mathrm{TiO}_{2}$, herein after referred to as $\mathrm{Ag}-\mathrm{TiO}_{2}$.

2.3. Charaterization of $\mathrm{TiO}_{2}$ and $\mathrm{Ag}-\mathrm{TiO}_{2}$ Nanoparticles. The phases of the synthesized particles were analyzed by JEOL JDX-II X-ray Diffractometer. Crystallite size of the prepared particles was determined from the broadening of the anatase main peak by the Scherrer equation. The external morphology of the particles was examined using an electron microscope JEOL JSM 6460. EDS analysis was carried out using the Oxford INCA X-sight 200 System.

2.4. The Photocatalysis Process. The schematic diagram of the experimental setup of photocatalysis experiment is shown in Figure $1.0 .004 \mathrm{~g}$ of high purity $p$-nitrophenol was dissolved in $200 \mathrm{ml}$ deionised water in a $250 \mathrm{ml}$ beaker and transferring it to a $1 \mathrm{~L}$ analytical flask. The beaker was thoroughly rinsed, twice, and the washings were added to the solution in the $1 \mathrm{~L}$ flask. The volume was made up, with deionised water, to $1 \mathrm{~L}$ to obtain a stock solution of $4 \mathrm{ppm} p$-nitrophenol.

An aliquot of the solution was taken and its $\mathrm{pH}$ (monitored with the HACH Sension $1 \mathrm{pH}$ meter) was adjusted to 7 with drop-wise addition of dilute $\mathrm{NaOH}(1 \mathrm{~N})$ solution. The resulting solution had a slight yellow tinge whose absorbance was measured at $400 \mathrm{~nm}$ in a $4 \mathrm{~cm}$ path length glass cell in a UV visible spectrophotometer (HACH DR 2400). Deionized water in a glass cell of the same dimensions served as a blank. The absorbance so obtained served as the reference value for determining the proportionate reduction in the concentration $\left(\mathrm{C}_{\circ}\right)$ of the phenol, after exposing the solution to UV light under the conditions of (a) no $\mathrm{TiO}_{2}$, (b) with $\mathrm{TiO}_{2}$, and (c) with $\mathrm{Ag}-\mathrm{TiO}_{2}$ as described below.

To investigate the photocatalytic degradation, p-nitrophenol solution of $4 \mathrm{ppm}$ was taken in a container. $\mathrm{Ag}-\mathrm{TiO}_{2}$ nanoparticles with a dose of $0.05 \mathrm{~g} / 50 \mathrm{ml}$ was added. It was placed under $20 \mathrm{~W}$ Blak-Ray UV lamp (with a wavelength peak at $365 \mathrm{~nm}$ and intensity of $1.4 \mathrm{~mW} / \mathrm{cm}^{2}$ ) and with continuous stirring. After every experiment the solution was centrifuged on (Sigma 204 instrument) at $4000 \mathrm{rpm}$ for 10 minutes. The degradation of centrifuged solution was measured at $400 \mathrm{~nm}$ on UV visible spectrophotometer (HACH DR 2400) and the degree of mineralization was carried out using Analytik jena TOC multi N/C 3100 analyzer.

Similar experiments were performed with 2,4-dichlorphenol, 2,5-dichlorophenol, and 2,4,6-trichlorophenol. Stock solutions of these compounds were prepared by dissolving $0.004 \mathrm{gm}$ of the above three compounds in dionized water and diluting to 1 liter. The cholorphenols were also exposed to UV light under conditions similar to those for $p$ ntirophenol. Here the baseline for the individual compounds was established by using the standard 4-aminpoantipyrene method [13].

\section{Results}

\section{1. $\mathrm{TiO}_{2}$ Nanoparticle Characterization}

3.1.1. X-Ray Diffraction. The crystal phase of laboratory prepared nanoparticles was identified using JEOL JDX-II X-ray diffractometer. XRD patterns are shown in Figure 2. The data indicates that the major phase of all the prepared nanoparticles is anatase. The crystallite size of prepared nanoparticles determined from the broadening of the anatase main peak by Scherrer equation [12] is shown in Table 1. $\mathrm{TiO}_{2}$ is in a range of $27 \mathrm{~nm}$ to $42 \mathrm{~nm}$ while the crystallite size of $\mathrm{Ag}-\mathrm{TiO}_{2}$ is $11.27 \mathrm{~nm}$ to $42.52 \mathrm{~nm}$. Our results are in consonance with those reported earlier [7] where Ag$\mathrm{TiO}_{2}$ nanoparticles dimensions were reported to be between $15 \mathrm{~nm}$ and $37 \mathrm{~nm}$,

$$
D_{p}=\frac{0.94 \lambda}{\beta_{1 / 2} \cos \theta}
$$

(see $[12])$.

3.1.2. EDS. The EDS-spectra of $\mathrm{TiO}_{2}$ (Figure 3) and Ag$\mathrm{TiO}_{2}$ (Figure 4) was obtained using the Oxford INCA Xsight 200 equipment. In similarity to an earlier work using EDS [7], the presence of three distinct X-ray lines associated with $\mathrm{O} \mathrm{K} \alpha, \mathrm{Ag} \mathrm{K} \alpha$, and $\mathrm{Ti} \mathrm{K} \alpha$, is clearly evident. The results 


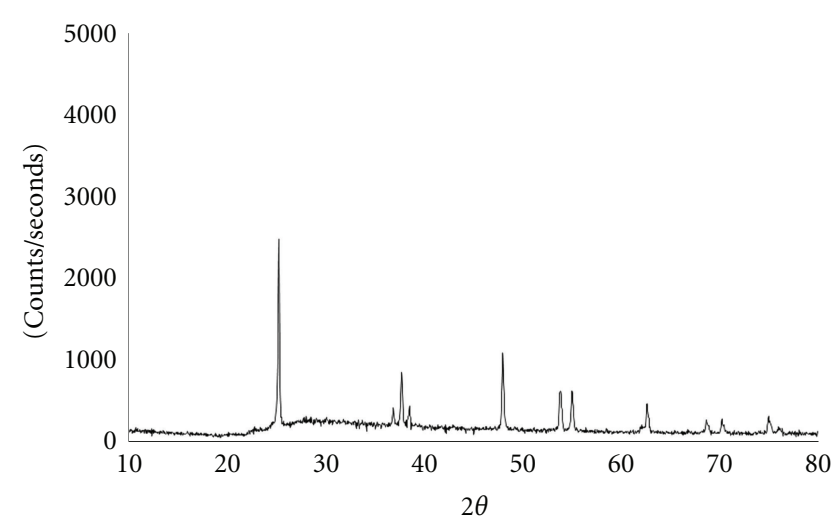

(a)

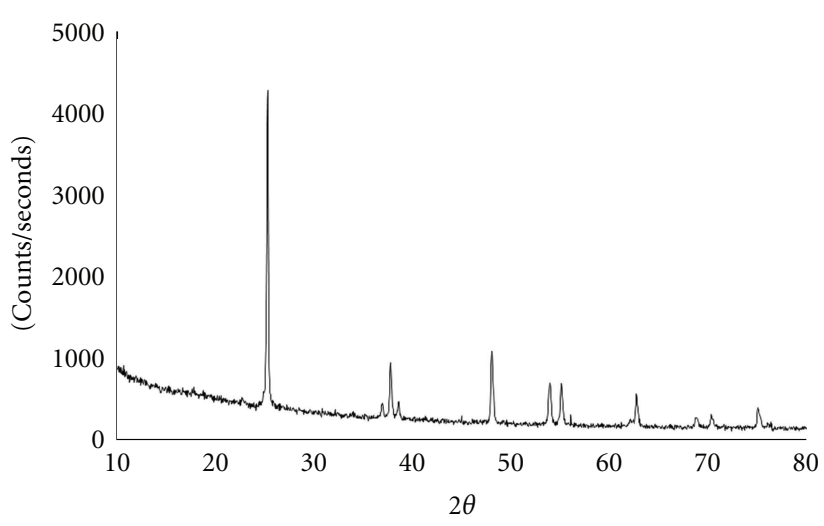

(b)

Figure 2: X-ray diffraction pattern (a) $\mathrm{TiO}_{2}$ (b) $\mathrm{Ag}^{-\mathrm{TiO}_{2}}$.

TABLE 1: Crystallite properties of undoped and Ag-doped $\mathrm{TiO}_{2}$.

\begin{tabular}{lccccc}
\hline \multirow{2}{*}{ Sr. No. } & \multirow{2}{*}{ Particles } & \multicolumn{2}{c}{ Particles Size $(\mathrm{nm})$} & Surface Area $\left(\mathrm{m}^{2} / \mathrm{g}\right)$ & \multirow{2}{*}{ Pore Diameter $\left({ }^{\circ} \mathrm{A}\right)$} \\
\hline 1 & ${\mathrm{Undoped} \mathrm{TiO}_{2}}$ & Maximum & Minimum & 74.30 & 131.06 \\
2 & $\mathrm{Ag}-\mathrm{TiO}_{2}$ & 42.52 & 26.72 & 77.74 & 129.65 \\
\hline
\end{tabular}

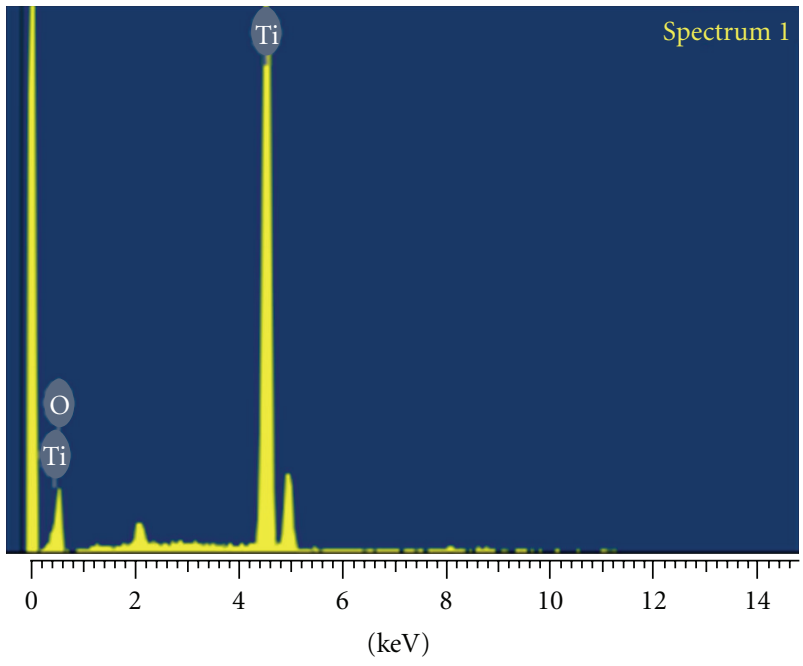

Full scale 929 cts cursor. $-0.201 \mathrm{keV}(0 \mathrm{cts})$

FIGURE 3: EDS pattern of $\mathrm{TiO}_{2}$ Nanoparticles prepared by Calcination.

indicate that $\mathrm{Ti}, \mathrm{O}$, and $\mathrm{Ag}$ are the constitutive elements of the nanoparticles prepared by the Liquid Impregnation method and no extraneous elements are present.

3.1.3. SEM. The SEM images of pure titania and Agdoped titania obtained using (JEOL JSM 6460 Scanning Electron Microscope) are shown in Figures 5 and 6 whereby the porous and sponge-like network of irregularly shaped particles is amply demonstrated. Surface roughness and

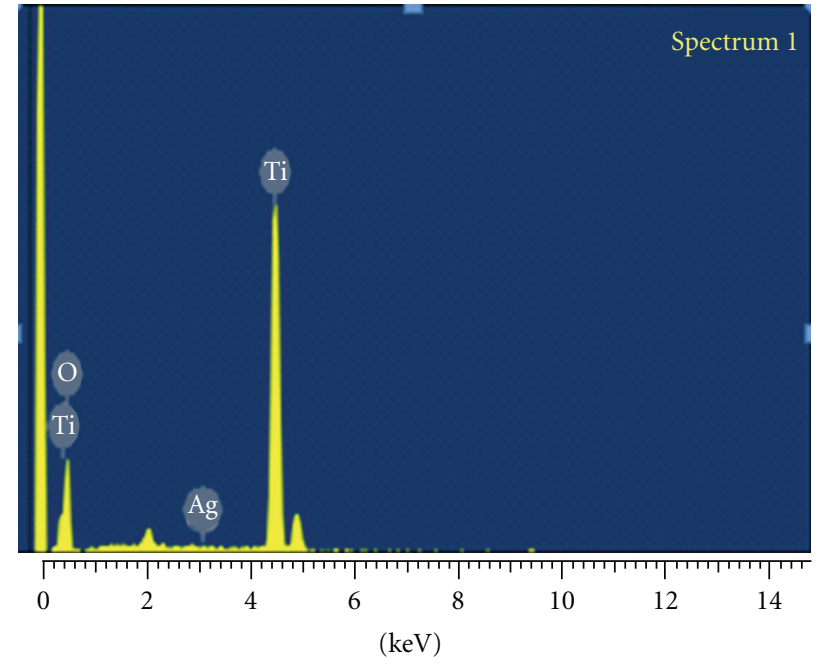

Full scale 929 cts cursor. $-0.201 \mathrm{keV}(0$ cts $)$

FIgure 4: EDS pattern of $\mathrm{Ag}-\mathrm{TiO}_{2}$ Nanoparticles prepared by Liquid Impregnation Method.

shaped complexity of the particles is high in case of Ag$\mathrm{TiO}_{2}$ which results in a high surface area. SEM images were taken from different sites of sample and then compared. The resulting image shows that silver is not uniformly deposited on the surface of titania nanoparticles, as found by other authors [12].

3.1.4. Surface Area and Pore Size Analysis. Figures 7 and 8 show the nitrogen adsorption isotherms and $\mathrm{BJH}$ pore 


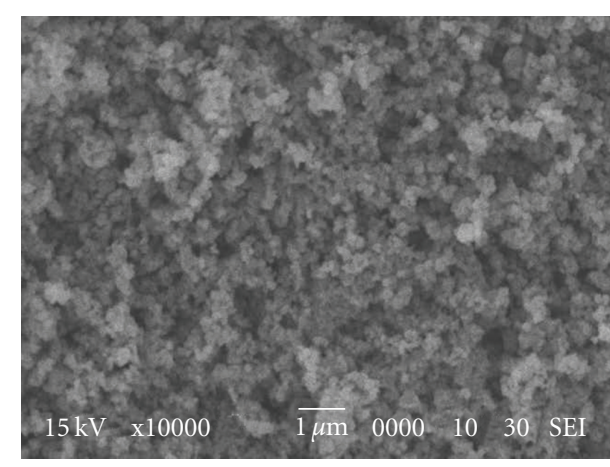

FIGURE 5: SEM micrograph of $\mathrm{TiO}_{2}$ nanoparticles.

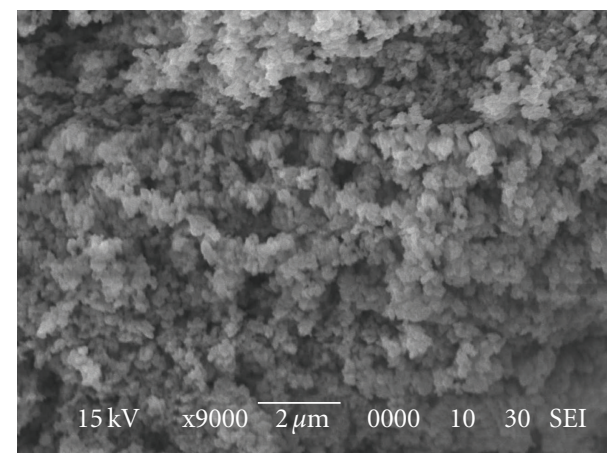

FIGURE 6: SEM micrograph of $\mathrm{Ag}-\mathrm{TiO}_{2}$ nanoparticles.

size distribution curves of doped $\mathrm{TiO}_{2}$ and undoped $\mathrm{TiO}_{2}$ samples, respectively, obtained by Surface and Pore Size Analyzer NOVA WIN 2200e. The Brunauer-Emmett-Teller (BET) specific surface areas and pore volumes of doped $\mathrm{TiO}_{2}$ and undoped $\mathrm{TiO}_{2}$ are summarized in Table 1. Results reveal that doping results in positive impact on surface area and pore diameter of the $\mathrm{TiO}_{2}$ nanoparticles.

\subsection{Optimization Studies.}

3.2.1. Photodegradation of p-Nitrophenol. For the optimization of the photocatalytic process, phototcatalytic degradation of $p$-nitrophenol with pure $\mathrm{TiO}_{2}$ was studied by varying the parameters of light intensity, $\mathrm{pH}$, and irradiation time. The concentration was determined by preparing the calibration curve of $p$-nirophenol on spectrophotometer.

3.2.2. Effect of UV Lamp Distance. The effect of UV light intensity on the degradation of $p$-nitrophenol was studied by varying the distance of UV lamp from the target. Figure 9 shows the relationship of UV light intensity in terms of lamp distance from the sample and percent photocatalytic degradation. As expected, the higher light intensity excited the $\mathrm{TiO}_{2}$ particles to generate more electron hole pairs. The holes decompose the $p$-nitrophenol molecules adsorbed on the surface of $\mathrm{TiO}_{2}$ particles and oxidize them to water resulting in their efficient degradation [14].
TABLE 2: Percent degradation of phenolic compounds in one hour.

\begin{tabular}{lll}
\hline Nanoparticles & Compounds & $\begin{array}{l}\text { Percentage } \\
\text { Degradation } \\
\text { in 1hr }\end{array}$ \\
\hline Pure $\mathrm{TiO}_{2}$ & p-nitrophenol & 83 \\
$\mathrm{Ag}-\mathrm{TiO}_{2}$ & p-nitrophenol & 98.3 \\
$\mathrm{Ag}-\mathrm{TiO}_{2}$ & 2,4-dichlorophenol & 98.9 \\
$\mathrm{Ag}-\mathrm{TiO}_{2}$ & 2,5-dichlorophenol & 98.55 \\
$\mathrm{Ag}-\mathrm{TiO}_{2}$ & 2,4,6-trichlorophenol & 96.41 \\
\hline
\end{tabular}

3.2.3. Effect of $p H$. The degree of photocatlytic degradation of $p$-nitrophenol was found to be affected by a change in $\mathrm{pH}$. Figure 10 shows that the photocatalytic degradation of p-nitrophenol was high between $\mathrm{pH} 2$ and $\mathrm{pH} 4$, while the degradation efficiency was lower in the alkaline environment above $7 \mathrm{pH}$. Titania surface will remain positively charged in acidic medium $(\mathrm{pH}<7)$ and negatively charged in alkaline medium $(\mathrm{pH}>7)$. Titanium dioxide is reported to have higher oxidizing activity at lower $\mathrm{pH}$ but excess $\mathrm{H}^{+}$at very low $\mathrm{pH}$ can decrease reaction rate. This observation confirms the finding of other researchers [15].

3.2.4. Degradation versus Irradiation Time. One of the very important parameters that was studied for the photocatalytic degradation of $p$-nitrophenol was time of degradation. The degradation rate was observed to increase with increase in irradiation time as shown in Figure 11.

In view of these results, subsequent experiments were caried out at a pH of 4 with UV lamp distance of $5 \mathrm{~cm}$ from the target surface of the solution in the china dish.

3.2.5. Comparative Degradation of p-Nitrophenol by Pure $\mathrm{TiO}_{2}$ and $\mathrm{Ag}-\mathrm{TiO}_{2}$. Comparitive photocatalytic degradation of $p$-nitrophenol was also investigated in the presence of UV light. $\mathrm{Ag}-\mathrm{TiO}_{2}$ nanoparticles show better results $(98 \%$ degradation) as compared to pure $\mathrm{TiO}_{2}$ nano particles $(83 \%$ degradation) in 1 hour as shown in Figure 12. This is due to the positive effect of silver on the photoactivity of $\mathrm{TiO}_{2}$ at degradation of $p$-nitrophenol that may be explained by its ability to trap electrons, thus, reducing the recombination of light-generated electron-hole pairs at $\mathrm{TiO}_{2}$ surface. These results encouraged the use of $\mathrm{Ag}$-doped $\mathrm{TiO}_{2}$ for the degradation of chlorophenols.

3.3. Photocatalytic Degradation of Cholophenols. When chlorination is done, phenols present in water react with chlorine to form chlorophenols. These chlorophenols are carcinogenic and impart an odour to the water making it unfit for secondary use. Three commonly known chlorophenols were selected which are 2,4-dichlorophenol, 2,5-dichlorophenol, and 2,4,6-trichlorophenol for the photocatalytic degradation using $\mathrm{Ag}-\mathrm{TiO}_{2}$ nanoparticles. The concentration was determined by preparing the calibration curves of chlorophenols using the 4-aminoantipyrine method [13].

As depicted in Figure 13, starting with the same initial concentration, the transformation rate of chlorophenols 


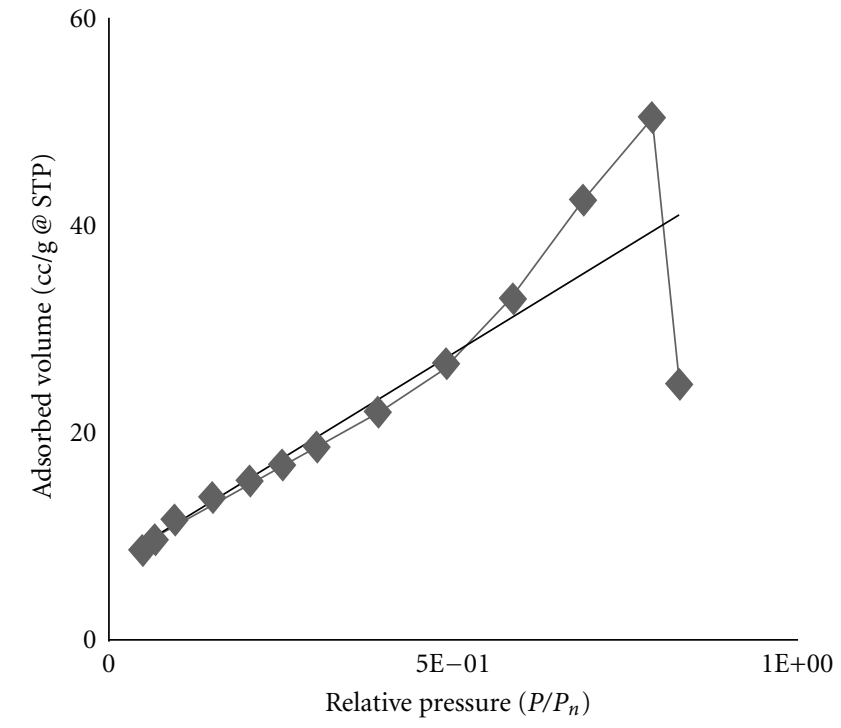

(a)

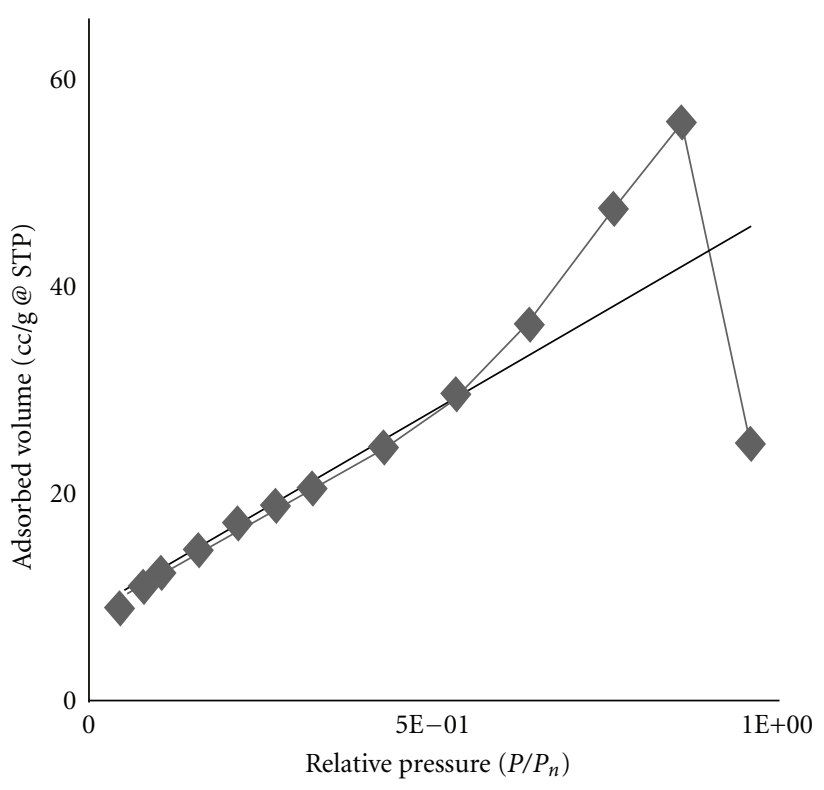

(b)

Figure 7: Nitrogen adsorption curve for doped and undoped $\mathrm{TiO}_{2}$ (a) Undoped $\mathrm{TiO}_{2}$ (b) Ag-doped $\mathrm{TiO}_{2}$.

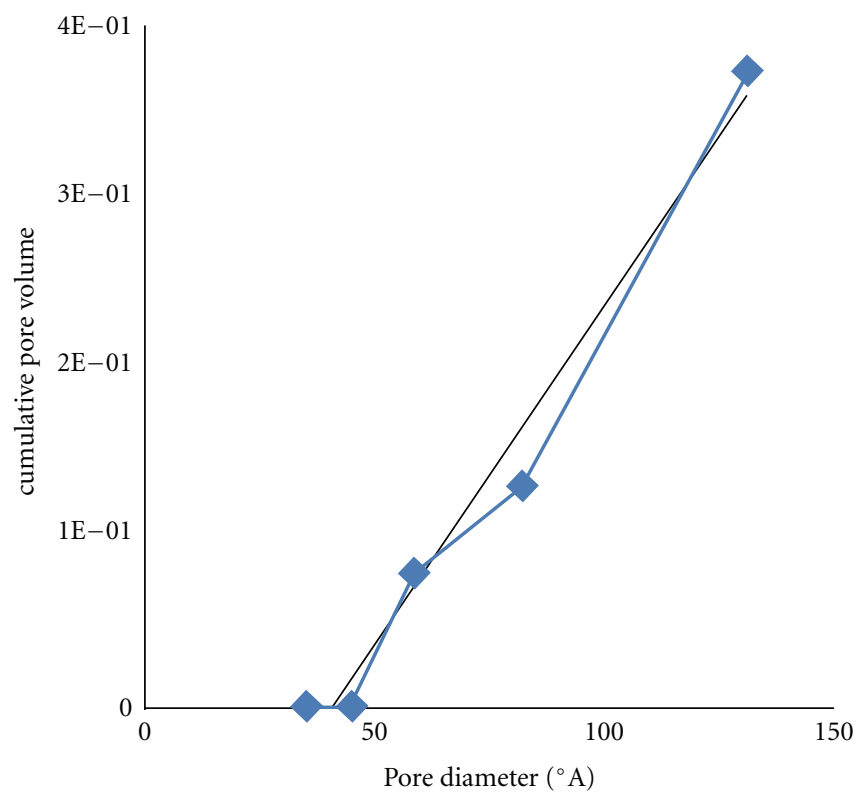

(a)

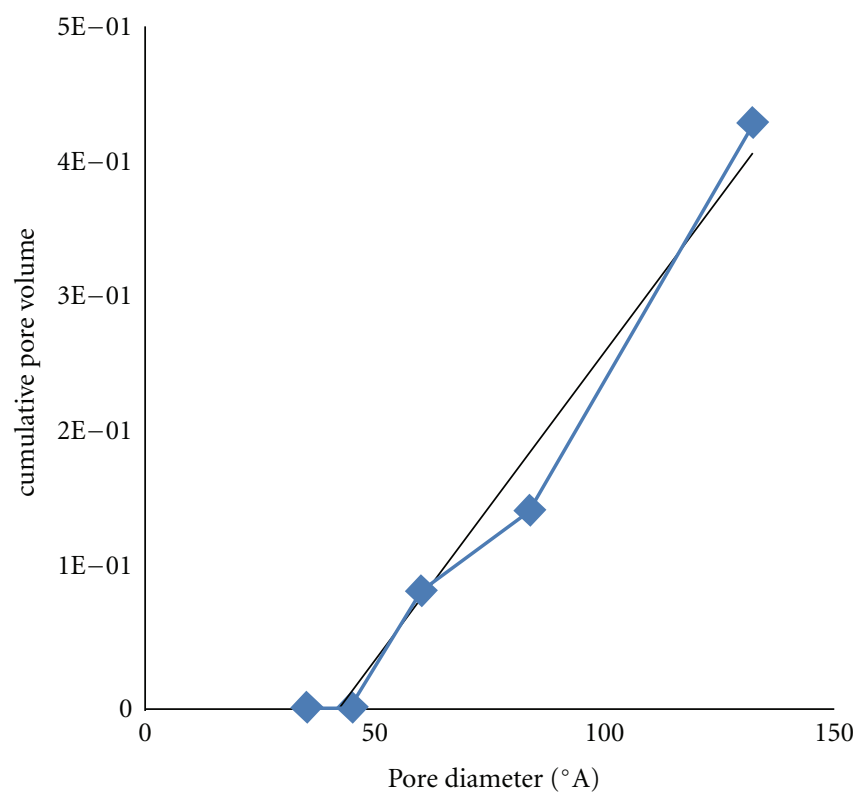

(b)

FIgUre 8: Pore size distribution curve for doped and undoped $\mathrm{TiO}_{2}$ (a) Undoped $\mathrm{TiO}_{2}$ (b) Ag-doped $\mathrm{TiO}_{2}$.

decreases as the number of chlorines on the phenolic ring increases. The addition of chlorine atom has previously been found to reduce the degradation rate of chlorophenols, [16]. In this study, it seems that the increase in the number of chlorine atoms on the phenolic ring makes the chlorophenols less responsive to UV degradation as the photo transformation rate of 2,4-DCP and 2,5-DCP was higher than that of 2,4,6TCP, as shown in Table 2.
3.4. Total Organic Carbon (TOC) Analysis. In the experimental work, photocatalytic degradation of the above discussed phenolic compounds was primarily monitored using absorption spectroscopy. This, however, does not indicate the degree of mineralization of the organic compounds. Following an earlier study [17], the oxidative mineralization was therefore examined by measuring the Total Organic Carbon (TOC) in the solution. The TOC measurements were 


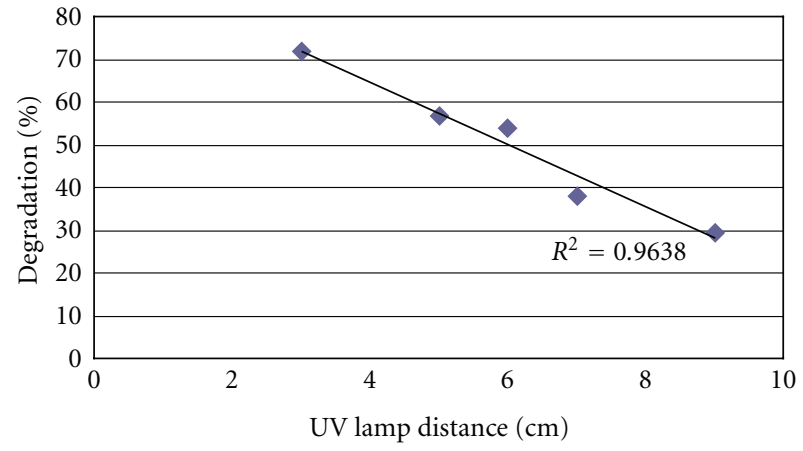

FIGURE 9: Effect of UV lamp distance on photodegradation of $p$ nitrophenol due to change in distance of UV lamp.

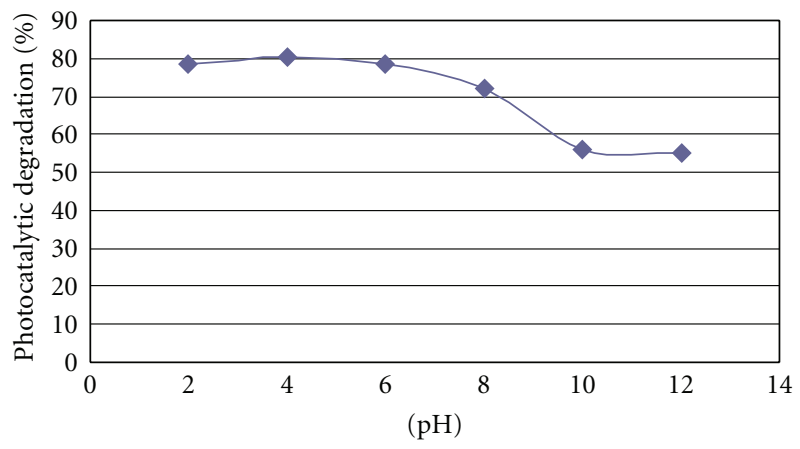

Figure 10: Represent the effect of change in $\mathrm{pH}$ on photocatalytic degradation of $p$-Nitrophenol.

TABle 3: Reaction Constants of photocatalytic process with $\mathrm{TiO}_{2}$ and $\mathrm{Ag}-\mathrm{TiO}_{2}$ for phenolic compounds.

\begin{tabular}{lcc}
\hline Nanoparticles & Compounds & $K^{\prime}\left(\mathrm{min}^{-1}\right) \times 10^{-2}$ a \\
\hline Pure $\mathrm{TiO}_{2}$ & p-nitrophenol & 2.4 \\
$\mathrm{Ag}-\mathrm{TiO}_{2}$ & p-nitrophenol & 6.6 \\
$\mathrm{Ag}-\mathrm{TiO}_{2}$ & 2,4-dichlorophenol & 7.7 \\
$\mathrm{Ag}-\mathrm{TiO}_{2}$ & 2,5-dichlorophenol & 6.2 \\
$\mathrm{Ag}-\mathrm{TiO}_{2}$ & 2,4,6-trichlorophenol & 3.6 \\
\hline
\end{tabular}

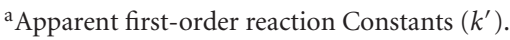

made using Analytik jena TOC multi N/C 3100 analyzer by direct injection of the aqueous solution after centrifugation.

As discussed above in photocatalytic degradation, the chlorophenols are converted into inorganic products like $\mathrm{CO}_{2}, \mathrm{H}_{2} \mathrm{O}$ and $\mathrm{CL}^{-}$[18]. Figure 14 gives the results of the TOC experiment indicating that 2,4-DCP was completely mineralized, while 2,5-DCP was mineralized up to 95 percent and 2,4,6-TCP upto 86 percent within the period of 120 minutes. The mineralization efficiency of the above said compounds was calculated by the following formula:

Mineralization efficiency

$$
=\frac{\text { TOC }(\text { stock })-\text { TOC }(\text { after Photocatalysis }) \times 100}{\text { TOC }(\text { stock })} .
$$

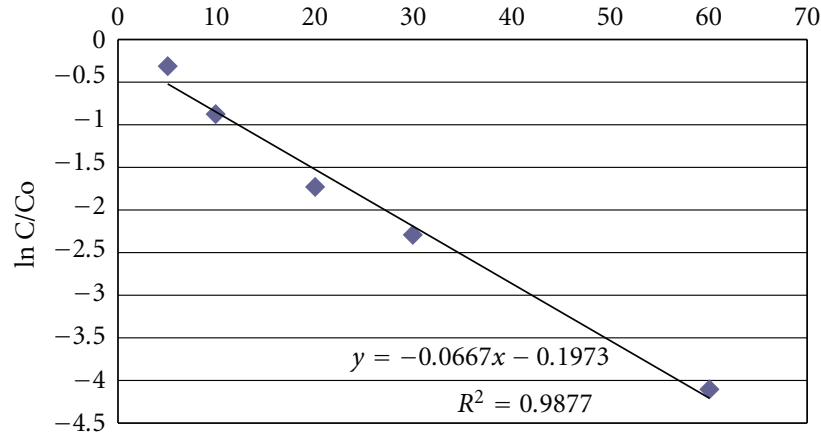

Time (min)

FIGURE 11: Photocatalytic degradation of $p$-Nitrophenol w.r.t irradiation time.

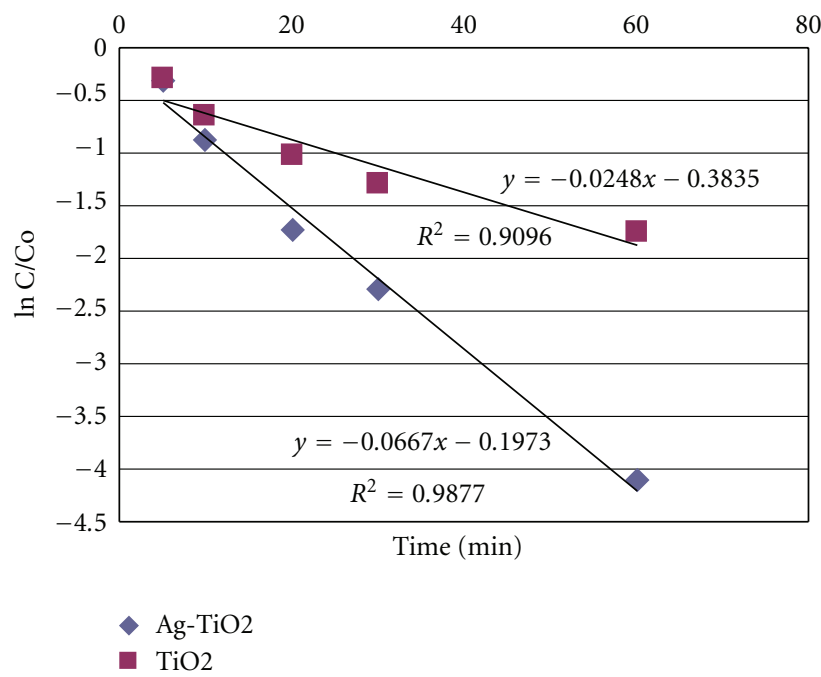

FIGURE 12: Comparitive photocatalytic degradation of $p$-nitrophenol with pure and Ag-doped Titania Nanoparticles.

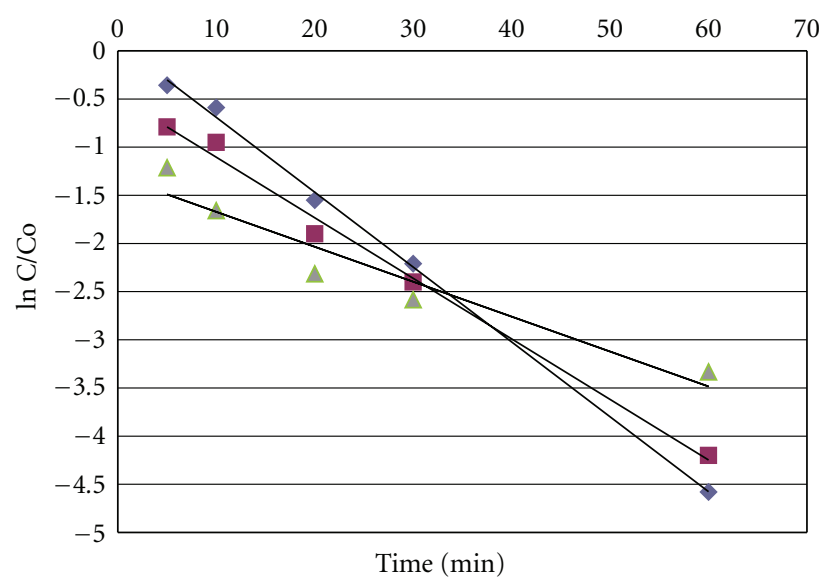

$$
\begin{aligned}
& \text { 2, 4-DCP } \\
& \text { - 2, 5-DCP } \\
& -2,4,6-\mathrm{TCP}
\end{aligned}
$$

Figure 13: Photocatalytic degradation of phenolic compounds using $\mathrm{Ag}-\mathrm{TiO}_{2}$ nanoparticle on spectrophotometer. 


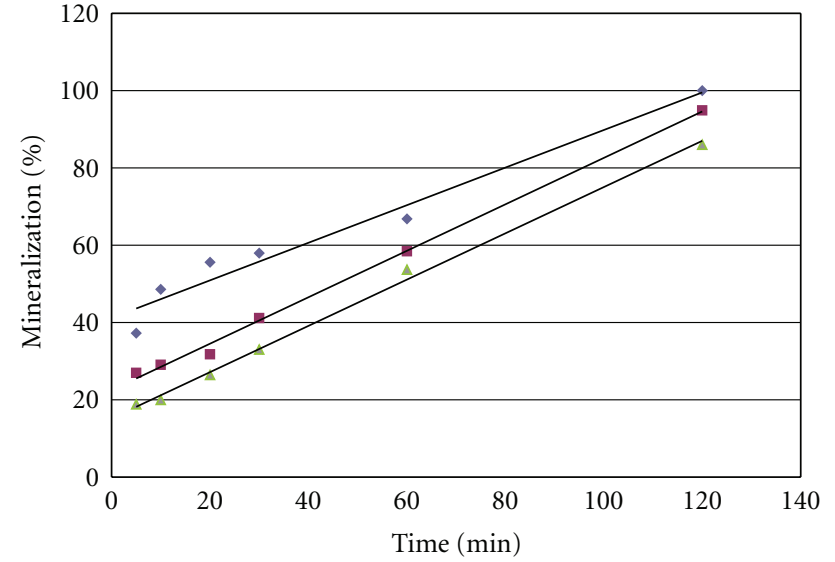

- 2, 4-DCP

- 2,5-DCP

4 2, 4, 6-TCP

Figure 14: Percent minerlization of phenolic compound based on TOC analysis.

3.5. The Reaction Kinetics. The photocatalytic degradation of organic pollutants generally follows the LangmuirHinshelwood mechanism [16],

$$
r=-\frac{d C}{d t}=k \theta=k \frac{K C}{1+K C}
$$

where $k$ is the true rate constant which depends upon mass of catalyst, the flux of efficient photons, and the coverage in oxygen. $K$ is the adsorption constant, $t$ is the time, and $C$ is the concentration of the organic pollutant. For the low initial concentrations of pollutants, the term $K C$, in the denominator, can be neglected and the photocatalytic oxidation rate approaches first order kinetics described by

$$
r=-\frac{d C}{d t}=k K C=k^{\prime} C
$$

where $k^{\prime}$, the apparent rate constant, is also known as the pseudo-first order rate constant. The integral form of the rate equation is

$$
\ln \frac{C}{C_{0}}=-k^{\prime} t
$$

where $C_{0}$ is the initial concentration.

Values of $k^{\prime}$ for experiments described in this study are given in Table $3 k^{\prime}$ values in Table 3 , compare well with the vales reported in a previous study [7], which used pure and 1 to $2 \mathrm{mmol} \mathrm{Ag-TiO}$ for degradation of $p$-nitrophenol as compared to $1 \%$ molar ratio in our case.

\section{Conclusion}

Pure $\mathrm{TiO}_{2}$ (42.52-26.72 nm), and silver-doped $\mathrm{TiO}_{2}$ (42.52$11.27 \mathrm{~nm}$ ) nanoparticles were synthesized through calcination and Liquid Impregnation method. Ag- $\mathrm{TiO}_{2}$ exhibited good potential for the photocatalytic degradation of phenolic compounds in acidic environment ( $\mathrm{pH} 4)$. More than 95\% photocatalytic degradation of phenolic compounds could be achieved in 1 hour using $\mathrm{Ag}-\mathrm{TiO}_{2}$ was achieved during 1 hour. Photocatalytic mineralization of 2,4-DCP (100\%), 2,5DCP (95\%), and 2,4,6-TCP (86\%) was achieved using Ag$\mathrm{TiO}_{2}$, after a period of 2 hours.

Langmuir-Hinshelwood kinetic model provided a good fit to the photocatalytic degradation of phenolic compounds, used in this study.

\section{References}

[1] T. Kudo, Y. Nakamura, and A. Ruike, "The design of highly active rectangular column-structured titanium oxide photocatalysts and their application in purification systems," Journal of Catalysis Today, vol. 122, pp. 14-19, 2003.

[2] G. Zayani, L. Bousselmi, F. Mhenni, and A. Ghrabi, "Solar photocatalytic degradation of commercial textile azo dyes: performance of pilot plant scale thin film fixed-bed reactor," Journal of Desalination, vol. 246, no. 1-3, pp. 344-352, 2009.

[3] U. I. Gaya and A. H. Abdullah, "Heterogeneous photocatalytic degradation of organic contaminants over titanium dioxide," Journal of Photochemistry and Photobiology C, vol. 9, no. 1, pp. 1-12, 2008.

[4] C. Guillard, J. Disdier, J.-M. Herrmann et al., "Comparison of various titania samples of industrial origin in the solar photocatalytic detoxification of water containing 4-chlorophenol," Journal of Catalysis Today, vol. 54, no. 2-3, pp. 217-228, 1999.

[5] W. A. Zeltner and D. T. Tompkin, Ashrae Transactions vol. III, vol. 2, American Society of Heating and Air-Conditioning Engineers, Atlanta, Ga, USA, 2005.

[6] C. Kormann, D. W. Bahnemann, and M. R. Hoffmann, "Preparation and characterization of quantum-size titanium dioxide," Journal of Physical Chemistry, vol. 92, no. 18, pp. 5196-5201, 1988.

[7] M. S. Lee, S.-S. Hong, and M. Mohseni, "Synthesis of photocatalytic nanosized $\mathrm{TiO}_{2}-\mathrm{Ag}$ particles with sol-gel method using reduction agent," Journal of Molecular Catalysis A, vol. 242, no. 1-2, pp. 135-140, 2005.

[8] D. Guin, S. V. Manorama, J. N. L. Latha, and S. Singh, "Photoreduction of silver on bare and colloidal $\mathrm{TiO}_{2}$ nanoparticles/nanotubes: synthesis, characterization, and tested for antibacterial outcome," Journal of Physical Chemistry C, vol. 111, no. 36, pp. 13393-13397, 2007.

[9] C. C. Wang, C. M. Lee, and C. H. Kuan, "Removal of 2,4-dichlorophenol by suspended and immobilized Bacillus insolitus," Journal of Chemosphere, vol. 41, no. 3, pp. 447-452, 2000.

[10] X.-H. Xu, W.-R. Zhao, Y.-Q. Huang, and D.-H. Wang, "2-chlorophenol oxidation kinetic by photo-assisted Fenton process," Journal of Environmental Sciences, vol. 15, no. 4, pp. 475-481, 2003.

[11] M. P. Ormad, J. L. Ovelleiro, and J. Kiwi, "Photocatalytic degradation of concentrated solutions of 2,4-dichlorophenol using low energy light. Identification of intermediates," Applied Catalysis B: Environmental, vol. 32, no. 3, pp. 157-166, 2001.

[12] M. A. Behnajady, N. Modirshahla, M. Shokri, and B. Rad, "Enhancement of photocatalytic activity of $\mathrm{TiO}_{2}$ nano particles by silver dopping: photodeposition versus liquid impregnation methods," Global NEST Journal, vol. 10, no. 1, pp. 1-7, 2008. 
[13] A. D. Eaton, L. S. Clesceri, E. W. Rice, and A. E. Greenberg, Standard Methods for Examination of Water and Wastewater, 21st edition, 2005.

[14] I. T. Horvàth, "Heterogeneous photocatalytic degradation of organic contaminants over titanium dioxide: a review of fundamentals, progress and problems," Journal of Encyclopedia Catalysis, vol. 5, p. 577, 2003.

[15] Z. Guo, R. Ma, and G. Li, "Photocatalytic property of colloidal $\mathrm{TiO}_{2}$ nanoparticles prepared by sparking process," Journal of Chemical Engineering, vol. 119, p. 55, 2006.

[16] J.-M. Herrmann, "Heterogeneous photocatalysis: state of the art and present applications," Journal of Catalysis, vol. 34, no. 1-4, pp. 49-65, 2005.

[17] D. Behar, C. Gonzalez, and P. Neta, "Reaction kinetics in ionic liquids: pulse radiolysis studies of 1-butyl-3methylimidazolium salts," Journal of Physical Chemistry A, vol. 105, no. 32, pp. 7607-7614, 2001.

[18] B. Neppolian, H. C. Choi, S. Sakthivel, B. Arabindoo, and V. Murugesan, "Solar light induced and $\mathrm{TiO}_{2}$ assisted degradation of textile dye reactive blue 4," Journal of Chemosphere, vol. 46, no. 8, pp. 1173-1181, 2002. 

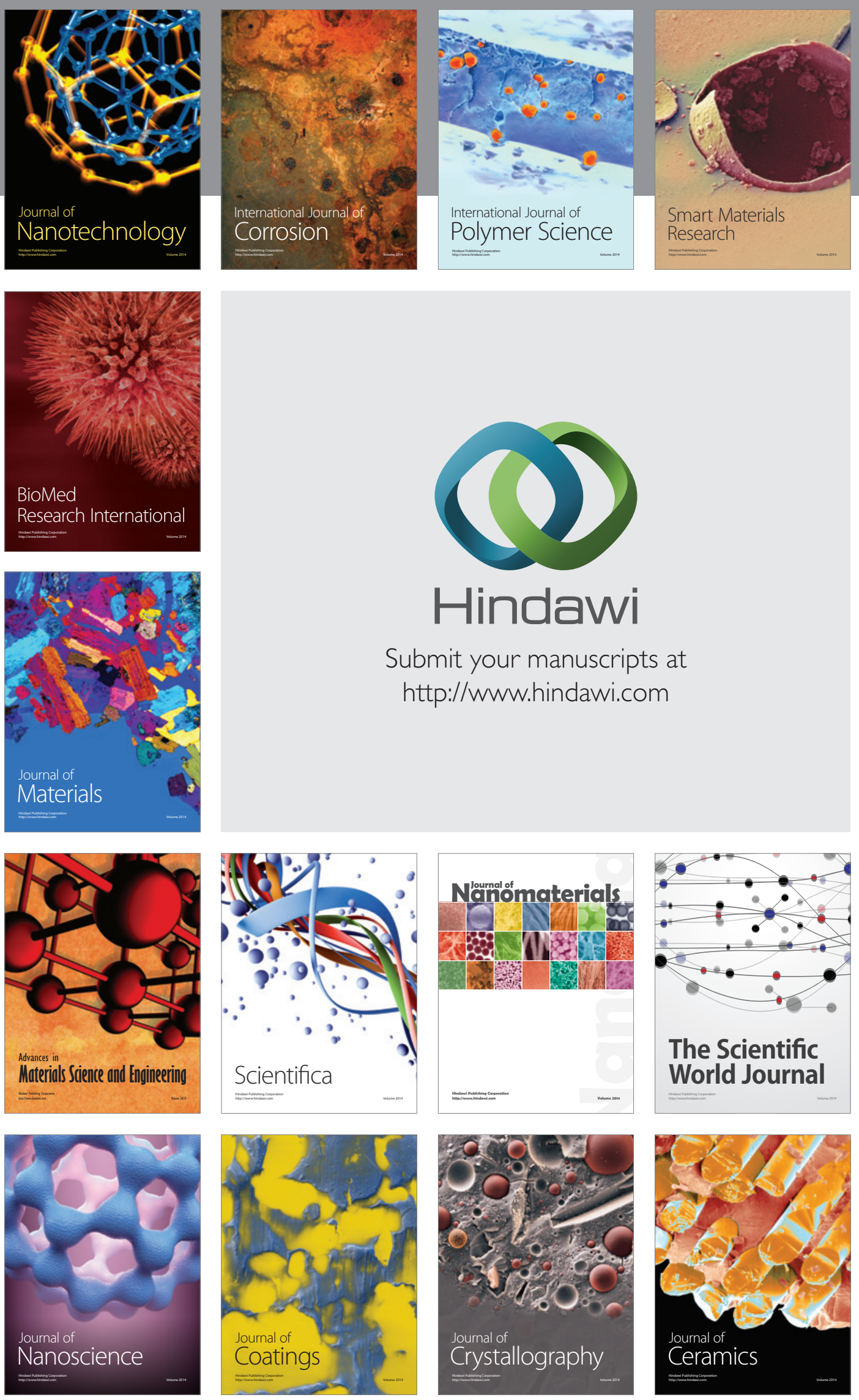

The Scientific World Journal

Submit your manuscripts at

http://www.hindawi.com

\section{World Journal}

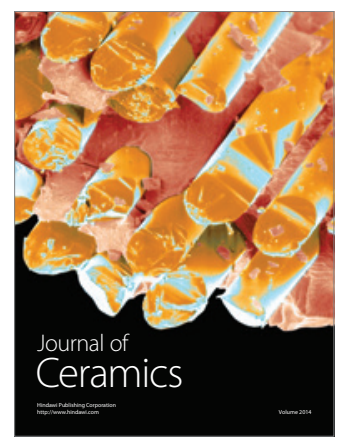

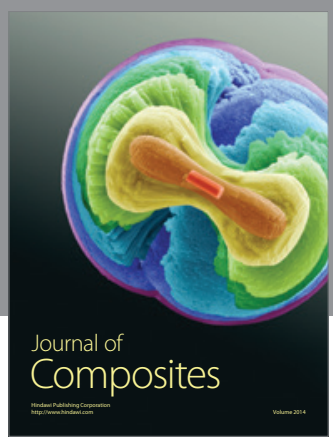
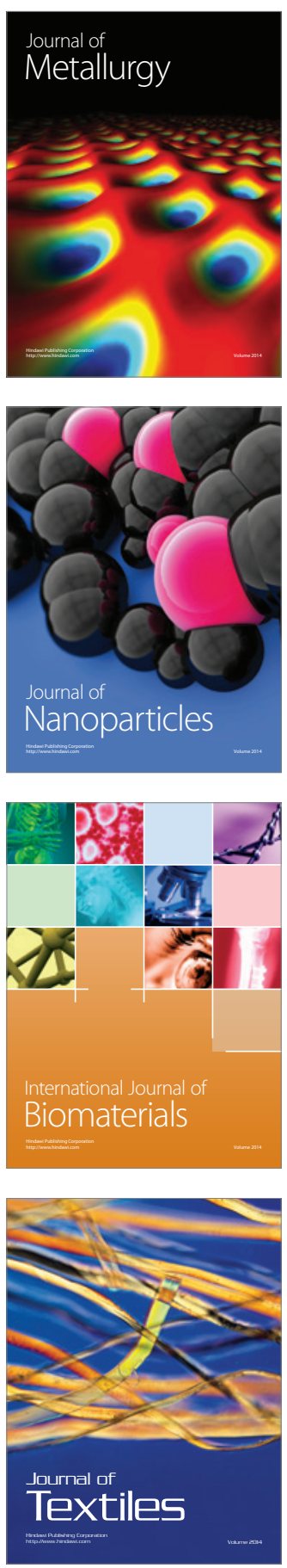